\title{
Current Status of Low Intensity Pulsed Ultrasound for Dental Purposes
}

\author{
Emanuel Braga Rego ${ }^{1,2, *}$, Takashi Takata ${ }^{1}$, Kazuo Tanne $^{2}$ and Eiji Tanaka ${ }^{3}$
}

\author{
${ }^{I}$ Department of Oral and Maxillofacial Pathobiology, Hiroshima University Graduate School of Biomedical Sciences, \\ Hiroshima, Japan \\ ${ }^{2}$ Department of Orthodontics and Craniofacial Developmental Biology, Hiroshima University Graduate School of Bio- \\ medical Sciences, Hiroshima, Japan \\ ${ }^{3}$ Department of Orthodontics and Dentofacial Orthopedics, Institute of Health Biosciences, The University of Tokushima \\ Graduate School, Tokushima, Japan
}

\begin{abstract}
Over the past few years, tissue engineering applied to the dental field has achieved relevant results. Tissue engineering can be described by actions taken to improve biological functions. Several methods have been described to enhance cellular performance and low intensity pulsed ultrasound (LIPUS) has shown to play an important role in cell metabolism. The present article provides an overview about the current status of LIPUS as a tissue engineering tool to be used to enhance tooth and periodontal regeneration.
\end{abstract}

Keywords: Ultrasound, tissue engineering, periodontal healing.

\section{INTRODUCTION}

Dental diseases affect millions of people worldwide. Tooth decay, periodontal disease, dental pulp infection and inflammatory root resorption can result in tooth loss and seriously compromise human health and quality of life. In this context, great efforts have been done to prevent oral diseases and restore teeth and periodontal integrity. Over the past few years, tissue engineering applied to the dental field has achieved relevant results. Tissue engineering can be described by actions taken to improve biological functions. Several methods have been described to enhance cellular performance and low intensity pulsed ultrasound (LIPUS) has shown to play an important role in cell metabolism. LIPUS stimulation is a classical therapeutic modality for bone regeneration and its efficiency has been widely reported over the years. Interestingly, recent studies have provided evidence that LIPUS plays an important role in the metabolism of periodontal cells and tissues as well. The present article provides an overview about the status of LIPUS stimulation as tool to be used to enhance tooth and periodontal regeneration.

\section{LIPUS AND BIOLOGIC MECHANISMS}

It is well known that mechanical stimulation plays a crucial role in regulating bone physiology. During bone remodeling, bone resorption and new bone formation are induced along the dominant local loading direction, suggesting that local regulation of bone remodeling is mediated by

\footnotetext{
*Address correspondence to this author at the Department of Oral and Maxillofacial Pathobiology, Hiroshima University Graduate School of Biomedical Sciences, 1-2-3 Kasumi, Minami-ku, Hiroshima 734-8553, Japan; Tel: +81-82-257-5686; Fax: +81-82-257-5687;

E-mail: emanuelbraga@hotmail.com
}

mechanical stimuli [1]. Osteoclasts initiate bone resorption in response to determined signals that may relate to local damage [2] and in response to a coupling signal, osteoblasts are recruited to deposit bone matrix, which is later mineralized [3]. The exact nature of the coupling signal is still unclear, but likely relates to local strain (deformation) levels. Osteoclast and osteoblast activity could thus be related to opposite strain modalities [4, 5].

It is well accepted that different patterns of mechanical stimulation can induce distinct cell response. During orthodontic tooth movement, for example, the networked reactions that occur in and around periodontal ligament and alveolar bone cells change compressive and tensile stresses into molecular events, resulting in bone resorption and formation, respectively [6]. Based on these evidences, various studies have been carried out to clarify the biological phenomena underlying orthodontic tooth movement. It has been shown experimentally that cells, located in the compression area, respond differentially from those on the tension side in terms of gene expression and enzymatic activity of bone metabolism regulators [7]. Other types of mechanical stimulation could thus modify cell metabolism, including ultrasound.

LIPUS (intensity ranging from $30-100 \mathrm{~mW} / \mathrm{cm}^{2}$ ) is an acoustic radiation that can be transmitted into the living tissues as pressure waves resulting in biochemical events at the cellular level [8]. LIPUS has been shown to stimulate bone and cartilage cells in vitro, indicating that ultrasound exerts direct anabolic effects such as production of growth factors and other signaling molecules, osteogenic differentiation and extra cellular matrix production [9]. The mechanisms involved in LIPUS-stimulated tissue repair have not been elucidated yet, however, it is recognized that the anabolic bio- 
physical effects caused by LIPUS are most likely to be caused by mechanical stress and/or fluid micro-streaming impacting on the cellular plasma membrane, focal adhesion and cytoskeletal structures to trigger intracellular signal transduction and subsequent gene transcription $[10,11]$.

\section{LIPUS AND BONE REGENERATION}

Mechanical stimulus to bone is of a great importance for maintaining the bone mass and structural stability of the skeleton. When bone is mechanically loaded, movement of fluid within the spaces surrounding bone cells generates fluid shear stress that stimulates osteoclasts and osteoblasts, resulting in enhanced anabolic activity for bone remodeling with appropriate bone resorption and the subsequent new bone formation. The mechanisms such as mechanotransduction process, by which osteoclasts or osteoblasts convert the external stimulation from fluid shear stress into biochemical changes, remain unclear [12].

In vivo studies have demonstrated that therapeutic LIPUS can promote bone repair and regeneration, accelerate bone fracture healing, and enhance osteogenesis at the distraction site [13-17]. It has also been shown in in vitro studies that LIPUS stimulation can enhance expression of bone formation-related genes such as collagen type I and X, aggrecan, transforming growth factor beta [18], runt related gene-2, osteocalcin [19], insulin-like growth factor-I, bone sialoprotein [20] and alkaline phosphatase [21]. In addition, LIPUS has been reported to promote protein synthesis and calcium uptake in various osteoblastic cell lines [22]. Moreover, LIPUS stimulation has been reported to enhance COX-2 gene expression and subsequently enhance endogenous prostaglandin $\mathrm{E}_{2}\left(\mathrm{PGE}_{2}\right)$ synthesis in various osteoblastic cell lineages, playing an important role in bone remodeling [23-25].

\section{LIPUS AND PERIODONTAL LIGAMENT REGEN- ERATION}

Physiologically, the periodontal ligament is continuously subjected to mechanical stress caused by occlusal forces. Furthermore, remodeling of the ligament and alveolar bone occurs in response to orthodontic forces. Taken together, these clearly indicate that responses of the ligament to mechanical stress are involved in its cell proliferation and differentiation. Periodontal ligament includes precursor cells of cementoblasts at the perivascular area in the middle portion and shows greater differentiation toward the surface of the root [26]. In a previous study, cyclic stretch stimulation mediated periodontal ligament cells differentiation, thus regulating the function of the periodontal ligament as a source of cementoblasts and osteoblasts through the EGF/EGF-R system [27].

Regarding LIPUS effects, it has been reported to be effective in releasing fibroblast growth factors from a macrophage-like cell line [28]. We have reported previously that LIPUS induced early cementoblastic differentiation of human immature cementoblasts from the periodontal ligament by promoting the formation of substrate and increasing alkaline phosphatase (ALP) activity, enabling the regeneration of periodontal tissue destroyed by periodontal disease and the acceleration of the repair of root resorption [29]. Mostafa et al. (2009) demonstrated that ALP and OPN expressions were also induced in human gingival fibroblasts treated with
LIPUS, confirming that after 3 weeks of $5 \mathrm{~min} /$ day exposure the osteogenic differentiation potential was enhanced [30].

\section{LIPUS AND CEMENTUM REGENERATION}

Cementum is a thin mineralized tissue covering the tooth root surface and assists in anchoring teeth to surrounding alveolar bone, maintaining the structural stability and physiological function of the dentition [31]. Resorption of the dental root surface can be a relevant adverse outcome of orthodontic treatment. A certain degree of root resorption occurs in most treatment cases, ranging from just a slight apical resorption to a complete tooth root loss [32-36]. It is well accepted that the cementum layer covering the root surface plays a crucial role in preventing resorption during tooth movement. In addition, the damaged areas are also repaired in part by cementoblasts lining the root surface. Root resorption during orthodontic treatment is thus confirmed as a multifactorial event and several biological and mechanical factors have been identified to increase its susceptibility, however, the cause still remains unclear [37].

Cementoblasts share many characteristics with osteoblasts, including similar molecular properties and the ability to promote mineralization $[38,39]$. Previous studies have shown that, as in bone, cementum metabolism is also controlled by mechanical stimulus. It has been reported that mechanical loading enhances the expression of phenotypic makers such as OCN and BSP in cementoblast in vivo; however, the expression was just moderately stimulated compared to osteoblasts [40]. Regarding ultrasound stimulation, a pioneer study published by El-Bially et al. (2004) showed that LIPUS prevented root resorption during experimental tooth movement in humans [41]. Studies performed by our group showed that LIPUS up-regulated the expression of several genes related to mineral metabolism in mouse cementoblasts $[42,43]$. We also reported in other article that LIPUS simulation significantly up-regulated COX-2 mRNA expression and enhanced $\mathrm{PGE}_{2}$ production inducing cementoblastic differentiation and matrix mineralization through EP2/EP4 prostaglandin receptors pathway [44].

Furthermore, we have also accessed the inhibitory effect of a 21-day LIPUS application on root resorption using an experimental model of tooth replantation involving luxation and immediate replacement of maxillary first molars in rats [45]. The results evidenced that the area of root resorption lacunae was statistically decreased in LIPUS treated sample. The imunne-expression of tumor necrosis factor alpha (TNF$\alpha$ ) was not observed in LIPUS treated sample as was evident as in the control sample. In addition, it was shown in vitro that LIPUS may contribute to the reduction of the trauma-induced inflammatory reaction through impairment of the TNF- $\alpha$ signaling pathway, suggesting that LIPUS shows potential as a therapeutic tool to optimize the regenerative potential of periodontal tissues on replanted teeth [45].

\section{LIPUS AND GINGIVAL REGENERATION}

Clinical trials applying LIPUS in implant dentistry have reported accelerated soft-tissue healing as well as osseointegration. In addition, it was suggested that the ultrasoundtreated wounds were at a more advanced stage in the repair process [28]. Despite, details of the clinical effects of LIPUS 
have not been well characterized, great efforts have been done to clarify the cellular mechanisms underlying LIPUSinduced tissue regeneration. Ikai et al. (2008) reported that a daily LIPUS treatment protocol of 20 minutes for a period of 4 weeks has a benefic effect on gingival epithelium cells, accelerating periodontal wound healing after flap surgery [46]. In other study using gingival epithelial cells, Shiraishi et al. (2011) reported that LIPUS accelerates soft-tissue healing by increasing the expression of connective tissue growth factor (CCN2/CTGF), an important gene for wound healing and angiogenesis in periodontal tissues [47].

\section{LIPUS AND IMPLANT OSSEOINTEGRATION}

The use of endosseous dental implants for replacing missing teeth increased considerable over the last few years and may be considered as the current most popular treatment option for edentulous patients. This fact might be related to the great effort on improving the osseointegration process. Attention has been given to the surface and shape of the implant $[48,49]$. Other approaches focused on acid etching of titanium surface [50], engineering of dental pulp cells on various implant surfaces [51] and biomimetic implant coatings containing bone morphogenetic protein-2 [52]. Other methods targeted on enhancement of endogenous bone healing around biomaterials through different forms of biophysical stimulations such as pulsed electromagnetic fields [53] or LIPUS [54].

A study of Tanzer et al. (1996) showed that LIPUS enhanced the rate and extent of bone growth into fully porouscoated implants inserted into dog femora [55]. Hsu et al. (2011) demonstrated in vivo that blood flow and mature type I collagen fibers were more prevalent around titanium implants, and bone formation was accelerated by ultrasound stimulation. In addition, tissue culture of MG63 osteoblastlike cells indicated that pulsed ultrasound effectively promoted cell migration and new bone regeneration [56]. Ustun et al. (2008) reported that the area, bone volume and boneimplant contact ratio values, which are significant parameters of histomorphometry assessments, have increased by LIPUS stimulation in tibial bone, suggesting that LIPUS application may accelerate and promote bone healing around dental implants leading to a higher quality and faster osseointegration [57].

\section{LIPUS AND PULP CELLS DIFFERENTIATION AND TOOTH ERUPTION}

Pulp tissue contains precursor cells which have the potential to differentiate into odontoblasts. It is well understood that after physiologic or pathologic stimulation pulp stem cells may be recruited to proliferate and differentiate into odontoblasts, which can produce dentin as a protection mechanism [58]. It is also well documented that LIPUS has the potential to induce bone and periodontal cells differentiation [13-17, 28-30]. In this context, the effect of LIPUS on pulp cells differentiation has risen as a subject of investigation. A previous study showed that LIPUS $\left(30 \mathrm{~mW} / \mathrm{cm}^{2}\right)$ promoted odontoblast-like cells differentiation through stimulation of vascular endothelial growth factor (VEGF) secretion [58]. It has also been shown that ultrasound stimulation $\left(0.5 \mathrm{~W} / \mathrm{cm}^{2}\right)$ induced pulp stem cells to form reparative dentin formation in vivo by optimizing gene transfer of growth/differentiation factor 11 plasmid DNA and subsequently up-regulation of dentin sialoprotein gene expression [59].

An interesting study of El-Bialy et al. (2003) examined the effect of therapeutic ultrasound on mandibular incisor development and eruption in mature rabbits undergoing mandibular osteodistraction. The results evidenced that ultrasound application combined with distraction enhanced mandibular incisor growth and eruption. Histologic examination showed that the newly formed tissues at the distraction site and at the cut ends of the incisor segments consisted of osteodentin-like tissue and cementum [60].

\section{LIPUS AND GENE DELIVERY}

Periodontal disease or inflammatory root resorption is relevant pathologic condition that can lead to tooth loss. In this regard, several tissue-engineering techniques have been proposed to restore periodontal integrity [61]. Administration of growth factors, for example, has proved to exert positive effect; however, some clinical limitations such as proteolytic degradation, rapid diffusion, and solubility of the delivery vehicle have been still problems to be solved [62]. In order to optimize the results, gene transfer methods were introduced; however, progress in experimental and clinical periodontal gene therapy is limited by the immunogenicity and cytotoxicity of viral vectors and low transfection efficiency with regard to non-viral vectors $[61,63]$. It has been reported that therapeutic ultrasound associated to echo contrast agents such as nano/microbubbles can optimize gene transfection in vitro and in vivo [63-67]. Recently, it has been shown that therapeutic ultrasound also provides an effective gene delivery system for bone and periodontal regeneration [68-70]. Because ultrasound-mediated osteogenic gene delivery has been just recently described, no consensus about optimal ultrasound intensity and its exposure protocol have been obtained yet. The use of LIPUS as a tool to optimize gene transfection was described by Watanuki et al. (2009). The study demonstrated that mouse calf muscles injected with BMP-4 plasmids and transcutaneous electroporated showed increased ectopic calcium and total collagen content and bone area when exposed to LIPUS [71].

\section{DISCUSSION}

Among the causes of teeth loss, inflammatory root resorption has received a great concern due to its unpredictability, difficult control and lack of biological understanding. the resorption of hard tissue in primary teeth is a normal physiologic phenomenon that leads to their exfoliation and ultimately the transition to permanent dentition. On the other hand, the hard tissues of permanent teeth are not resorbed under healthy conditions and the resorption is thus considered a pathologic process [72]. Different causes have been attributed to the root resorption process including pressure, inflammation, neoplastic process and systemic conditions [73]; however, the biological phenomena underlying root resorption are still not completely understood. Tooth root resorption is regarded as a major problem encountered after tooth replantation and orthodontic tooth movement. Eventually, the progression and severity of root resorption cannot 
be controlled and culminate with the complete tooth loss. Approaches aiming to attenuate or inhibit root resorption and restore periodontal integrity during the dental practice are still the subject of debate and investigation. Some therapeutic approaches have been proposed to inhibit root resorption after tooth replantation and can induce periodontal regeneration [74-77]. However, with respect to root resorption induced by orthodontic tooth movement, less-accepted clinical protocols have been established, probably due to the difficult application and/or possibly side effects that medicamentous treatment can generate. In this context, non-invasive modality such as LIPUS therapy has been given increased attention and risen as promising therapeutic tool for the regeneration of periodontium.

The effectiveness of LIPUS for bone regeneration is already universally accepted and some recent papers have provided evidence that it can exert benefic effects in other kinds of tissues, including teeth. In addition, LIPUS presents low toxicity, low immunogenicity, non-invasiveness, highly targeted selectivity, and repeated applicability. However, the diversity of techniques, application protocols and ultrasound specifications found in the literature may cause confusion for the clinician. Bains et al. (2008) have pointed out that ultrasound application in both diagnosis and periodontal therapy seems to present promising results; however, long-term evidence-based studies are required to use ultrasound in routine periodontal practice [78].

\section{CONCLUSIONS}

Despite LIPUS therapy has been widely used in the fields of orthopedic surgery and rehabilitation, its availability by dental professionals is still incipient. The effects of LIPUS in bony tissue seem to be well understood, but the literature has still lacked for available information about its effects on periodontal tissues. The present review brings out current evidence that LIPUS has a positive effect on tooth and periodontal cells metabolism, suggesting that LIPUS can be a promising therapeutic tool for the regeneration of tooth support tissues.

\section{CONFLICT OF INTEREST}

The authors confirm that this article content has no conflicts of interest.

\section{ACKNOWLEDGEMENTS}

Declared none.

\section{REFERENCES}

[1] Petrtyl M, Hert J, Fiala P. Spatial organization of the haversian bone in man. J Biomech 1996; 29: 1619.

[2] Burr DB, Milgrom C, Fyhrie D, Forwood M, Nyska M, Finestone A. In vivo measurement of human tibial strains during vigorous activity. Bone 1996; 18: 40510.

[3] Everts V, Delaisse JM, Korper W, Jansen DC, Tigchelaar-Gutter $\mathrm{W}$, Beertsen W. The bone lining cell: Its role in cleaning Howship's lacunae and initiating bone formation J Bone Miner Res 2002; 17: 77-90.

[4] Smit TH, Burger EH. Is BMU-coupling a strain-regulated phenomenon? a finite element analysis. J Bone Miner Res 2000; 15: $301-7$.
[5] Smit TH, Burger EH, Huyghe JM. A case for strain-induced fluid flow as a regulator of BMU-coupling and osteonal alignment. $\mathrm{J}$ Bone Miner Res 2002; 17: 2021-9.

[6] Masella RS, Meister M. Current concepts in the biology of orthodontic tooth movement. Am J Orthod Dentofacial Orthop2006; 129: 458-68.

[7] Tan SD, Xie R, Klein-Nulend J, Van Rheden RE, Bronckers AL, Kujipers-Jagtman AM, Van den Hoff JW, Maltha JC. Orthodontic force stimulates eNOS and iNOS in rat osteocytes. J Dent Res 2009; 88: 255-60.

[8] Buckley MJ, Banes AJ, Levin LG, et al. Osteoblasts increase their rate of division and align in response to cyclic mechanical tension in vitro. Bone Miner 1998; 4: 225-36.

[9] Claes L, Willie B. The enhancement of bone regeneration by ultrasound. Prog Biophys Mol Biol 2007; 93: 384-98.

[10] Khan Y, Laurencin CT. Fracture repair with ultrasound: clinical and cell-based evaluation. J Bone Joint Surg 2008; 90: 138-44.

[11] Romano CL, Romano D, Logoluso N. Low-intensity pulsed ultrasound for the treatment of bone delayed union or nonunion: a review. Ultrasound Med Biol 2009; 35: 529-36.

[12] Young SR, Gerard-O'Riley R, Kim JB, Pavalko FM. Focal adhesion kinase is important for fluid shear stress-induced mechanotransduction in osteoblasts. J Bone Miner Res 2009; 3: 411-24.

[13] Duarte LR. The stimulation of bone growth by ultrasound. Arch Orthop Trauma Surg 1983; 101: 153-9.

[14] Dyson M. Therapeutic applications of ultrasound. In: Biological effects of ultrasound. Nyborg WL, Ziskin MC, Eds. Churchill Livingstone, New York, NY 1985; pp. 121-33.

[15] El-Bialy TH, Royston TJ, Magin RL, Evans CA, ZakiAel M, Frizzell LA. The effect of pulsed ultrasound on mandibular distraction. Ann Biomed Eng 2002; 30: 1251-61.

[16] Gebauer D, Correll J. Pulsed low-intensity ultrasound: a new salvage procedure for delayed unions and nonunions after leg lengthening in children. J Pediatr Orthop 2005;6:750-4.

[17] Erdogan O, Esen E, U“ stun Y, et al. Effects of low-intensity pulsed ultrasound on healing of mandibular fractures: an experimental study in rabbits. J Oral Maxillofac Surg 2006; 64: 180-8.

[18] Mukai S, Ito H, Nakagawa Y, Akiyama H, Miyamoto M, Nakamura $\mathrm{T}$. Transforming growth factor- $\beta 1$ mediates the effects of low-intensity pulsed ultrasound in chondrocytes. Ultrasound Med Biol 2005; 31: 1713-21.

[19] Chen YJ, Wang CJ, Yang KD, et al. Pertussis toxin-sensitive Gai protein and ERK dependent pathways mediate ultrasound promotion of osteogenic transcription in human osteoblasts. FEBS Lett 2003; 554: 154-8.

[20] Naruse K, Mikuni-Takagaki Y, Azuma Y, et al. Anabolic response of mouse bone-marrow-derived stromal cell clone ST2 cells to lowintensity pulsed ultrasound. Biochem Biophys Res Commun 2000; 268: 216-20.

[21] Warden SJ, Favaloro JM, Bennell KL, et al. Low-intensity pulsed ultrasound stimulates a bone forming response in UMR-106 cells. Biochem Biophys Res Commun 2001; 286: 443-50.

[22] Naruse K, Miyauchi A, Itoman M, Mikuni-Takagaki Y. Distinct anabolic response of osteoblasts to low-intensity pulsed ultrasound J Bone Miner Res 2003; 18: 360-9.

[23] Kokubu T, Matsui N, Fujioka H, Tsunoda M, Mizuno K. Low intensity pulsed ultrasound exposure increases prostaglandin $\mathrm{E}_{2}$ production via the induction of cyclooxygenase-2 mRNA in mouse osteoblasts. Biochem Biophys Res Commun 1999; 256: 284-7.

[24] Saito M, Fujii K, Tanaka T, Soshi S. Effect of low and high intensity pulsed ultrasound on collagen post-translational modifications in MC3T3-E1 osteoblasts. Calcif Tissue Int 2004; 75: 384-95.

[25] Tang CH, Yang RS, Huang TH, et al. Ultrasound stimulates cyclooxygenase-2 expression and increases bone formation through integrin, focal adhesion kinase, phosphatidylinositol 3-kinase, and Akt pathway in osteoblasts. Mol Pharmacol 2006; 69: 2047-57.

[26] Bosshardt DD, Degen T, Lsng NP. Sequence of protein expression of bone sialoprotein and osteopontin at the developing interface between repair cementum and dentin in human deciduous teeth. Cell Tissue Res 2005; 320: 399-407.

[27] Matsuda N, Yokoyama K, Takeshita, S, Watanabe M. Role of epidermal growth factor and its receptor in mechanical stressinduced differentiation of human periodontal ligament cells in vitro. Arch Oral Biol 1998; 43: 987-97.

[28] Young SR, Dyson M. The effect of therapeutic ultrasound on angiogenesis. Ultrasound Med Biol 1990; 16: 261-9. 
[29] Inubushi T, Tanaka E, Rego EB, et al. Effects of ultrasound on the proliferation and differentiation of cementoblast lineage cells. J Periodontol 2008; 79: 984-90.

[30] Mostafa NZ, Uludağ H, Dederich DN, Doschak MR, El-Bialy TH. Anabolic effects of low-intensity pulsed ultrasound on human gingival fibroblasts. Arch Oral Biol 2009; 54: 743-8.

[31] Ten Cate AR. The periodontium: Oral histology, development, structure and function. Mosby, St Louis, MO 2003; 276-9.

[32] Hollender L, Ronneman A, Thilander B. Root resorption, marginal bone support and clinical crown length in orthodontically treated patients. Eur J Orthod 1980; 2:197-205.

[33] Levander E, Malmgren O. Evaluation of the risk of root resorption during orthodontic treatment: a study of upper incisors.Eur J Orthod 1988; $10: 30-8$

[34] Linge L, Linge BO. Patient characteristics and treatment variables associated with apical root resorption during orthodontic treatment. Am J Orthod Dentofacial Orthop 1991; 99: 35-43.

[35] Levander E, Malmgren O, Eliasson S. Evaluation of root resorption in relation to two orthododntic treatment regimes. A clinical experimental study. Eur J Orthod 1994; 16: 223-8.

[36] Kurol J, Owman-Moll P, Lundgren D. Time related root resorption after application of a controlled continuous orthodontic force. Am J Orthod Dentofacial Orthop 1996; 110: 303-10.

[37] Rita FN, David EW, James LG. Tooth resorption. Quint Int 1999; 30: $9-25$

[38] Matias MA, Li H, Young WG, Bartold PM. Immunohistochemical localization of extracellular matrix proteins in the periodontium during cementogenesis in the rat molar. Arch Oral Biol 2003; 48: 709-16.

[39] Bosshardt DD. Are cementoblasts a subpopulation of osteoblasts or a unique phenotype? J Dent Res 2005; 84: 390-406.

[40] Pavlin D, GluhakJ. Effect of mechanical loading on periodontal cells. Crit Rev Oral Biol Med 2001; 12: 414-24

[41] El-Bialy T, El-Shamy I, Graber TM. Repair of orthodontically induced root resorption by ultrasound in humans. Am J Orthod Dentofacial Orthop 2004; 126: 186-93.

[42] Dalla-Bona DA, Tanaka E, Oka H, et al. Effects of ultrasound on cementoblast metabolism in vitro. Ultrasound Med Biol 2006; 32: 943-8.

[43] Dalla-Bona DA, Tanaka E, Inubushi T, et al. Cementoblast response to low- and high-intensity ultrasound. Arch Oral Biol 2008; 53: 318-23.

[44] Rego EB, Inubushi T, Kawazoe A, et al. Ultrasound stimulation induces PGE2 synthesis promoting cementoblastic differentiation through EP2/EP4 receptor pathway. Ultrasound Med Biol 2010; 36: $907-15$.

[45] Rego EB, Inubushi T, Miyauchi M, et al. Ultrasound stimulation attenuates root resorption on rat replanted molars and impairs TNF$\alpha$ signaling in vitro. J Periodont Res 2011; 46: 648-54.

[46] Ikai H, Tamura T, Watanabe T, et al.Low-intensity pulsed ultrasound accelerates periodontal wound healing after flap surgery. $\mathrm{J}$ Periodont Res 2008; 43: 212-6.

[47] Shiraishi R, Masaki C, Toshinaga A, et al, Hosokawa R. The effects of low-intensity pulsed ultrasound exposure on gingival Cells. J Periodontol 2011; 82: 1498-503.

[48] Brånemark PI, Zarb G, Albreksson T. Tissue-integrated prosthesis. In: Brånemark PI, editor. Osseointegration in clinical dentistry. Chicago, Il: Quintessence Publishing Co; 1985; pp. 11-76.

[49] Buser D, Schenk RK, Steinmann S, Fiorellini JP, Fox CH, Stich H. Influence of surface characteristics on bone integration of titanium implants. A histomorphometric study in miniature pigs. J Biomed Mater Res 1991; 25: 889-902.

[50] Ericsson I, Johansson CB, Bystedt H, Norton MR. A histomorphometric evaluation of bone-to-implant contact on machineprepared and roughened titanium dental implants: a pilot study in the dog. Clin Oral Implant Res 1994; 5: 202-6.

[51] Klokkevold PR, Johnson P, Dadgostari S, Caputo A, Davies JE, Nishimura RD. Early endosseous integration enhanced by dual acid etching of titanium: a torque removal study in the rabbit. Clin Oral Implant Res 2001; 12: 350-7.

[52] Nakamura H, Saruwatari L, Aita H, Takeuchi K, Ogawa T. Molecular and biomechanical characterization of mineralized tissue by dental pulp cells on titanium. J Dent Res 2005; 86: 515-20.

[53] Liu Y, DE Groot K, Hunkizer EB. BMP-2 liberated from biomimetic implant coatings induces and sustains direct ossification in an ectopic rat model. Bone 2005; 36: 745-57.
[54] Fini M, Giavaresi G, Setti S, Martini L, Torricelli P, Giardino R. Current trends in the enhancement of biomaterial osteointegration: Biophysical stimulation. Biomaterials 2004; 27: 681-90.

[55] Tanzer M, Harvey E, Kay A, Morton P, Bobyn JD. Effect of noninvasive low intensity ultrasound on bone growth into porouscoated implants. J Orthop Res 1996; 14: 901-6.

[56] Hsu SK, Huang WT, Liu BS, Li SM, Chen HT, Chang CJ. Effects of near-field ultrasound stimulation on new bone formation and osseointegration of dental titanium implants in vitro and in vivo.Ultrasound Med Biol 2011; 37: 403-16.

[57] Ustun Y, Erdogan O, Kurkcu M, Akova T, Damlar I. Effects of low-intensity pulsed ultrasound on dental implant osseointegration: a preliminary report. Eur J Dent 2008; 2: 254-62.

[58] Scheven BA, Man J, Millard JL, et al. VEGF and odontoblast-like cells: stimulation by low frequency ultrasound. Arch Oral Biol 2009; 54: 185-91.

[59] Nakashima M, Tachibana K, Iohara K, Ito M, Ishikawa M, Akamine A. Induction of reparative dentin formation by ultrasoundmediated gene delivery of growth/differentiation factor 11. Hum Gene Ther 2003; 14: 591-7.

[60] El-Bialy TH, el-MoneimZaki A, Evans CA. Effect of ultrasound on rabbit mandibular incisor formation and eruption after mandibular osteodistraction. Am J Orthod Dentofacial Orthop 2003; 124: 42734

[61] Ramseier CA, Abramson ZR, Jin Q, Giannobile WV. Gene therapeutics for periodontal regenerative medicine. Dent Clin North Am 2006; 50: 245-63.

[62] Pradeep AR, Karthikeyan BV. Tissue engineering: prospect for regenerating periodontal tissues. Indian J Dent Res 2003; 14: 2249 .

[63] Nishida K, Doita M, Takada T, et al. Sustained transgene expression in intervertebral disc cells in vivo mediated by microbubbleenhanced ultrasound gene therapy. Spine 2006; 31: 1415-9.

[64] Dijkmans PA, Juffermans LJ, Musters RJ, et al. Microbubbles and ultrasound: from diagnosis to therapy. Eur J Echocardiogr 2004; 5: 245-56.

[65] BekeredjianR, Grayburn PA, Shohet RV. Use of ultrasound contrast agents for gene or drug delivery in cardiovascular medicine. $\mathrm{J}$ Am Coll Cardiol 2005; 45: 329-35.

[66] Shimamura M, Sato N, Taniyama Y, et al. Development of efficient plasmid DNA transfer into adult rat central nervous system using microbubble-enhanced ultrasound. Gene Ther 2004; 11: 1532-9.

[67] Aoi A, Watanabe Y, Mori S, Takahashi M, Vassaux G, Kodama T. Herpes simplex virus thymidine kinase-mediated suicide gene therapy using nano/microbubbles and ultrasound. Ultrasound Med Biol 2008; 34: 425-34.

[68] Sheyn D, Kimelman-Bleich N, Pelled G, Zilberman Y, Gazit D, Gazit Z. Ultrasound-based nonviral gene delivery induces bone formation in vivo. Gene Ther 2008; 15: 257-66.

[69] Chen R, Chiba M, Mori S, Fukumoto M, Kodama T. Periodontal gene transfer by ultrasound and nano/microbubbles. J Dent Res 2009; 88: 1008-13.

[70] Osawa K, Okubo Y, Nakao K, Koyama N, Bessho K. Osteoinduction by microbubble-enhanced transcutaneous sonoporation of human bone morphogenetic protein-2. J Gene Med 2009; 11: 633-41.

[71] Watanuki M, Kishimoto KN, Kotajima S, Iwabuchi S, Kokubun S. Effect of low-intensity pulsed ultrasound on scaffold-free ectopic bone formation in skeletal muscle. Ups J Med Sci 2009; 114: 2428.

[72] Gunraj MN. Dental root resorption. Oral Surg Oral Med Oral Pathol Oral Radiol Endod 1999; 88: 647-53

[73] Ravindran S, Chaudhary M, Tumsare M, Patil S, Wadhwan V. A Scanning electron microscopic study of the patterns of external root resorption under different conditions. J Appl Oral Sci 2009; 17: 481-6.

[74] Loberg EL, Engstrom H. Thyroid administration to reduce root resorption. Angle Orthod 1994; 64: 395-9.

[75] Igarashi K, Adachi H, Mitani H, Shinoda H. Inhibitory effect of the topical administration of a bisphosphonate (risedronate) on root resorption incident to orthodontic tooth movement in rats. J Dent Res 1996; 75: 1644-9.

[76] Talic NF, Evans C, Zaki AM. Inhibition of orthodontically induced root resorption with echistatin, an RGD-containing peptide. Am J Orthod Dentofacial Orthop 2006; 129: 252-60. 
[77] Fujishiro N, Anan H, Hamachi T, Maeda K. The role of macrophages in the periodontal regeneration using Emdogain ${ }^{\circledR}$ gel. J Periodont Res 2008; 43: 143-55.
[78] Bains VK, Mohan R, Bains R. Application of ultrasound in periodontics: Part II. J Indian Soc Periodontol 2008; 12: 55-61.

(C) Braga Rego et al.; Licensee Bentham Open.

This is an open access article licensed under the terms of the Creative Commons Attribution Non-Commercial License (http://creativecommons.org/licenses/by-nc/3.0/) which permits unrestricted, non-commercial use, distribution and reproduction in any medium, provided the work is properly cited. 